\title{
Quantification of diabetes consultations by the main primary health care nurse groups in Auckland, New Zealand
}

\author{
Barbara Daly $^{1}$, Bruce ArrolI ${ }^{2}$, Nicolette Sheridan ${ }^{3}$, Timothy Kenealy $^{4}$ and Robert Scragg ${ }^{5}$ \\ ${ }^{1}$ Senior Lecturer in Nursing, School of Nursing, Faculty of Medical and Health Sciences, University of Auckland, \\ Auckland, New Zealand \\ ${ }^{2}$ Professor of Department of General Practice \& Primary Health Care, School of Population Health, University of \\ Auckland, Auckland, New Zealand \\ ${ }^{3}$ Associate Professor in Nursing, School of Nursing, Faculty of Medical and Health Sciences, University of Auckland, \\ Auckland, New Zealand \\ ${ }^{4}$ Associate Professor of Departments of Medicine and General Practice \& Primary Health Care, School of Population \\ Health, University of Auckland, Auckland, New Zealand \\ ${ }^{5}$ Professor of Epidemiology and Biostatistics, School of Population Health, University of Auckland
}

\begin{abstract}
Background: Diabetes prevalence continues to increase, with most diabetes patients managed in primary care. Aim: This report quantifies the number of diabetes consultations undertaken by primary healthcare nurses in Auckland, New Zealand. Methods: Of 335 primary healthcare nurses randomly selected, $287(86 \%)$ completed a telephone interview in 2006-2008. Findings: On a randomly sampled day (from the past seven) for each nurse, $42 \%$ of the nurses surveyed $(n=120)$ consulted 308 diabetes patients. From the proportion of nurses sampled in the study, it is calculated that the number of diabetes patients consulted by primary healthcare nurses per week in Auckland between September 2006 and February 2008 was 4210, with $61 \%$ consulted by practice, $23 \%$ by specialist and $16 \%$ by district nurses. These findings show that practice nurses carry out the largest number of community diabetes consultations by nurses. Their major contribution needs to be incorporated into future planning of the community management of diabetes.
\end{abstract}

Key words: diabetes management; primary healthcare nurses; nurse consultations

Received 13 January 2014; revised 11 November 2015; accepted 29 November 2015;

first published online 8 January 2016

\section{Introduction}

The burden of diabetes in New Zealand (NZ) continues to grow (Ministry of Health, 2014), which along with the lack of specialist diabetes healthcare professionals (New Zealand Society for the Study of Diabetes, 2009) has increased the need for primary health care (PHC) nurses to take on an expanded role in the overall management of diabetes in the community. However, the contribution by PHC nurses to the community management of diabetes

Correspondence to: Barbara Daly, School of Nursing, Faculty of Medical and Health Sciences, University of Auckland, Auckland 1142, New Zealand. Email: b.daly@auckland.ac.nz has not been quantified previously. Increased understanding of their contribution will potentially assist healthcare managers in the planning of future community-based services for diabetes patients.

The largest of the four main groups of $\mathrm{PHC}$ nurses who are involved in the management of diabetes are practice nurses (PNs) based in general practice, whereas district nurses (DNs) are employed by secondary-care services and predominantly provide home care for patients. Diabetes specialist nurses (DSN) are based in secondary care and provide specialist care for patients with type 1 and type 2 diabetes. Chroniccare management $(\mathrm{CCM})$ nurses provide care for patients with chronic conditions and work for

(C) Cambridge University Press 2016 
community-based independent healthcare providers and in general practice (Daly et al., 2013a).

Previous findings from this study show that most PHC nurses are involved in the community management of diabetes. Over half of PNs and DSN partially or fully complete Diabetes Annual Reviews (Daly et al., 2013b), carry out foot examinations for almost half of all patients consulted (Daly et al., 2014b) and focus management and health promotion on improving blood glucose levels (Daly et al., 2015). In contrast, gaps in knowledge (Daly et al., 2014a) and practice related to cardiovascular risk management (smoking, blood pressure and lipids) were identified (Daly et al., 2014c).

This paper quantifies the daily number of diabetes consultations undertaken by PHC nurses and compares the number of diabetes consultations undertaken by practice, district and specialist nurses (SNs) to better understand the workload distribution undertaken by community-based nurses in Auckland, NZ.

\section{Methods}

PHC nurses were recruited into a cross-sectional survey between September 2006 and February 2008. All PNs were identified from a current list held by the Department of General Practice and Primary Health Care, University of Auckland. Lists for DNs and DSN were obtained from the three Auckland District Health Boards. Community-based DSN and CCM nurses were identified by contacting all 19 Primary Health Organisations and the three independent Māori healthcare providers. A total of 1091 PHC nurses were identified (813 PNs, 180 DNs, 73 DSN and 25 CCM nurses). Nurses were stratified by group, and a similar proportion was randomly sampled from each group to give a total of 383 , of whom 335 $(88 \%)$ were currently working and were invited to participate. Ethics approval was granted by the Northern Regional Ethics Committee of the NZ Ministry of Health (NTX/05/10/128), which included approval to interview nurses and collect anonymous information about diabetes patients seen by them on a single randomly selected day.

All the participants completed a consent form and a self-administrated questionnaire, which were mailed to them and were returned in a replypaid envelope. This questionnaire collected biographic and workplace details and has been described previously (Daly et al., 2013a). Nurses were asked how many hours they worked in a typical week' with the following possible responses: '8 or less', '9-16', '17-24', '25-39' and '40 or more'. A follow-up telephone interview was arranged with all the participating nurses. This was designed to elicit further information on the nursing management of diabetes patients and document the number of diabetes consultations each nurse undertook during a typical work day. Towards the end of the interview, each nurse was asked what days they had worked over the past seven; the days stated were entered into a computer software programme that randomly selected one of the days, so that each day had an equal probability of selection. Participants were then asked how many hours they had worked on the randomly selected day and how many diabetes consultations they had carried out. Questionnaires are available from the corresponding author on request.

\section{Data analysis}

All nurses were categorised as PNs, DNs or SNs. The latter included the DSN and CCM nurses who were combined for all analyses because of their small numbers. The chi-squared test was used to compare the distribution of variables by nurse group with PROC FREQ in SAS version 9.2 (SAS Institute, Cary, NC, 2008). The total number of consultations carried out by the sampled nurses per week was calculated, for each nurse, by multiplying the number of diabetes consultations per hour worked on the randomly selected day by the midpoint of the category of hours worked per week (or 40 hours if $\geqslant 40$ ). These values were then summed for each nurse group to represent a typical working week during the study period. To calculate the number of consultations carried out by all PHC nurses in the greater Auckland area per week, the number of nurses in each nurse group was multiplied by the inverse of the sampling probability for each nurse group (footnoted in Table 2) to extrapolate to the total PHC nurse population for Auckland.

\section{Results}

Of the 335 nurses invited, 287 (86\%) nurses $-26 \%$ of all PHC nurses in Auckland - agreed to 
participate and all of them completed a telephone interview; of those, 284 completed and returned the self-administered questionnaire. The numbers of participating nurses from each list of nurses were 213 PNs, 49 DNs and 25 SNs (19 DSN and 6 CCM). However, four PNs re-classified themselves as SNs, and one $\mathrm{SN}$ was re-classified as a PN, so that the self-reported numbers of PNs and SNs were 210 and 28, respectively, and the number of DNs remained unchanged. The self-reported nurse group numbers were used for data analyses. Most nurses were female (98\%), 86\% were aged over 40 years, $73 \%$ were of NZEuropean ethnicity and $49 \%$ held or were completing post-registration qualifications. Most PNs $(92 \%)$ and $54 \%$ of SNs worked in general practice, whereas all DNs consulted patients in their homes.

Table 1 outlines the total number of nurses sampled, the number of hours worked and the number of patients consulted on the randomly selected day (Table 1). Most SNs and DNs worked at least eight hours on the randomly selected day, significantly more than PNs, reflecting the greater proportion $(73 \%)$ of PNs who worked part-time. Over $70 \%$ of PNs worked between Monday and Thursday with significantly fewer working on Fridays (66\%) compared with DNs (86\%) and SNs $(82 \%, P=0.009)$, whereas significantly more DNs worked on Saturdays (27\%) and Sundays (18\%) compared with PNs and SNs $(P=0.046$ and 0.02$)$, respectively. On the randomly sampled day, a significantly greater proportion of SNs $(54 \%)$ had consulted more than one diabetes patients compared with DNs (29\%) and PNs (19\%, $P=0.002)$. The median number of patients consulted was one, two and four to five by PNs, DNs and SNs, respectively. In addition, a greater proportion of SNs $(50 \%)$ consulted at least three diabetes patients, including one who briefly consulted 28 patients for retinal screening. The proportion of non-responders was not significantly different across the nurse groups (Table 1).

Table 2 reports on the number of patient consultations by the sampled nurses and on the calculated values for the total number of PHC nurses in Auckland. Of the 287 nurses who participated in the telephone interview, 120 consulted a total of 308 patients. Of those patients, 28 were consulted briefly by one specialist ophthalmology nurse, who was excluded as an outlier. PNs consulted the majority of the 280 patients on the randomly selected day (58\%) compared with SNs $(25 \%)$ and DNs (17\%). After correcting for the number of hours worked per week by each of the sampled nurses, it was estimated that they consulted a total of 1123 patients per week, with the percentages consulted by nurse group being PNs $60 \%$, SNs $24 \%$ and DNs $16 \%$ (Table 2). Allowing for the sampling probabilities for each nurse group based on their self-reported nurse group status, we estimated that a total of 4210 patients were consulted by all PHC nurses in Auckland each week during the study period (PNs $61 \%$, SNs $23 \%$ and DNs $16 \%$ ). On the basis of the original list classification of nurse group status, our estimate of diabetes patients consulted each week

Table 1 Hours worked and number of nurses who consulted diabetes patients on the randomly selected day $(n=287)$

\begin{tabular}{|c|c|c|c|c|c|}
\hline \multirow[t]{2}{*}{ Variable and level } & \multirow[t]{2}{*}{ Total $(n)$} & \multicolumn{3}{|c|}{ Type of nurse } & \multirow[t]{2}{*}{$P$-value } \\
\hline & & Practice nurses $(n)$ & District nurses $(n)$ & Specialist nurses $(n)$ & \\
\hline Total nurse sample & 287 & 210 & 49 & 28 & \\
\hline $\begin{array}{l}\text { Hours worked and the nu } \\
\text { Hours worked }(n=283) \\
3-7.75 \\
8 \\
8.5-12\end{array}$ & $\begin{array}{l}\text { ber of nurs } \\
n(\%) \\
63(22) \\
126(45) \\
94(33)\end{array}$ & $\begin{array}{l}\text { seeing specified nur } \\
n(\%) \\
57(28) \\
77(37) \\
73(35)\end{array}$ & $\begin{array}{l}\text { er of patients } \\
\qquad n(\%) \\
4(8) \\
33(67) \\
12(24)\end{array}$ & $\begin{array}{c}n(\%) \\
2(7) \\
16(59) \\
9(33)\end{array}$ & 0.0004 \\
\hline $\begin{array}{l}\text { Number of nurses who c } \\
0 \text { patients } \\
1 \text { patient } \\
>1 \text { patient } \\
\text { Non-responders }\end{array}$ & $\begin{array}{r}\text { sulted }(n= \\
166(58) \\
52(18) \\
68(24) \\
48(14)\end{array}$ & $\begin{array}{l}86) \\
130(62) \\
40(19) \\
39(19) \\
37(15)\end{array}$ & $\begin{array}{r}26(53) \\
9(18) \\
14(29) \\
10(17)\end{array}$ & $\begin{aligned} 10(36) \\
3(11) \\
15(54) \\
1(3.5)\end{aligned}$ & $\begin{array}{l}0.002 \\
0.20\end{array}$ \\
\hline
\end{tabular}

$P$-value showing significance of variation in percentages in subgroups, from the log-likelihood chi-square value.

Primary Health Care Research \& Development 2016; 17: 524-529 
Table 2 Nurses who consulted patients on a randomly selected day by patient number and hours worked

\begin{tabular}{|c|c|c|c|c|c|}
\hline \multirow[t]{2}{*}{ Variable and level } & \multirow{2}{*}{$\begin{array}{l}\text { Total } \\
{[n(\%)]}\end{array}$} & \multicolumn{3}{|c|}{ Type of nurse } & \multirow[t]{2}{*}{$P$-value } \\
\hline & & $\begin{array}{l}\text { Practice } \\
\text { nurses } \\
{[n(\%)]}\end{array}$ & $\begin{array}{l}\text { District } \\
\text { nurses } \\
{[n(\%)]}\end{array}$ & $\begin{array}{l}\text { Specialist } \\
\text { nurses } \\
{[n(\%)]}\end{array}$ & \\
\hline $\begin{array}{l}\text { Total nurses who consulted } \geq 1 \text { patients } \\
\text { Hours worked per week }\end{array}$ & $120(42)$ & $79(38)$ & $23(47)$ & $18(64)$ & \\
\hline $9-16$ & $7(6)$ & $5(6)$ & $1(4)$ & $1(6)$ & \\
\hline $17-24$ & $15(13)$ & $11(14)$ & $3(13)$ & $1(6)$ & 0.20 \\
\hline $25-39$ & $49(42)$ & $36(46)$ & $10(43)$ & $3(18)$ & \\
\hline$\geqslant 40$ & $47(40)$ & $26(33)$ & $9(39)$ & $12(71)$ & \\
\hline Total & $118(100)$ & $78(66)$ & $23(19)$ & $17(14)$ & \\
\hline \multicolumn{6}{|l|}{ Hours worked on randomly selected day } \\
\hline 3-7.75 & $17(15)$ & $15(19)$ & $1(4)$ & $1(6)$ & \\
\hline 8 & $57(49)$ & $34(44)$ & $14(61)$ & $9(56)$ & 0.30 \\
\hline $8.5-12$ & $43(37)$ & $29(37)$ & $8(35)$ & $6(38)$ & \\
\hline Total & $117(100)$ & $78(67)$ & $23(20)$ & $16(14)$ & \\
\hline Total patients consulted on the sampled day & $280^{\mathrm{a}}$ & $163(58)$ & $47(17)$ & $70^{a}(25)$ & \\
\hline $\begin{array}{l}\text { Calculated total number of consultations by sampled } \\
\text { nurses (by self-reported roles) per week }\end{array}$ & $\begin{array}{l}1123 \\
n=278\end{array}$ & $\begin{array}{l}669^{b}(60) \\
n=204\end{array}$ & $\begin{array}{c}183^{\mathrm{b}}(16) \\
n=48\end{array}$ & $\begin{array}{l}271^{\mathrm{b}}(24) \\
n=26\end{array}$ & \\
\hline $\begin{array}{l}\text { Calculated number of diabetes consults by all nurses } \\
\text { (by self-reported roles) in Auckland per week }\end{array}$ & 4210 & $2589^{c}(61)$ & $672^{\mathrm{C}}(16)$ & $949^{c}(23)$ & \\
\hline
\end{tabular}

$P$-value showing significance of variation in percentages in subgroups, from chi-square value using Pearson's exact tests. a 28 patients who consulted one specialist ophthalmology nurse are excluded from all analyses.

${ }^{\mathrm{b}}$ Calculations are described in the methods.

${ }^{c}$ The total estimated number of consultations carried out by all primary healthcare nurses in Auckland per week using self-reported nursing roles and is based on the number of consultations carried out by the $26-27 \%$ of sampled nurses and multiplied by the appropriate factor (PNs $\times 3.87, \mathrm{DNs} \times 3.67, \mathrm{SNs} \times 3.50$ ).

by all PHC nurses was 4283 (PNs 2666, SNs 945, DNs 672). The ophthalmology nurse who consulted 28 patients on the randomly selected day typically conducted three ophthalmology clinics per week and carried out pupil dilation and retinal screening in 20 to 30 patients during each daily clinic. When the calculation for self-reported nurse group status was repeated with the 28 patients included, 383 diabetes patients had been consulted on the randomly selected day by the SNs, 1235 per week by all sampled nurses and 4602 patients per week by all PHC nurses in Auckland.

\section{Discussion}

To our knowledge, this is the first report on the number of diabetes patients consulted per day by PHC nurses and the distribution by nurse group. Findings from this survey show that PNs consult the largest number of patients and on average consult one diabetes patient a day and collectively over 2500 per week in Auckland. This equates to nearly half the number of diabetes consultations undertaken by GPs, at the time of the study, and based on 57200 people with diabetes living in Auckland (Ministry of Health 2008) who on average consult their GPs five times per year (Robinson et al., 2006). Further, these survey findings are supported by the national health survey data on the increasing acceptance by patients who consult PNs, with almost 23\% of children (Ministry of Health, 2008) and $31 \%$ of NZ adults annually consulting a PN without visiting a GP at that time (Ministry of Health, 2014). In addition, the majority of GPs also support an expanded role for PNs as they are costeffective and save GPs' time (Finlayson et al., 2009), and most nurses felt supported in the management of diabetes (Daly et al., 2013a). A recent retrospective observational study undertaken in the United Kingdom involving 471 general practices caring for $6 \%$ of the population reported that nurses carried out about $30 \%$ of all diabetes consultations during 2002 to 2011, although the sample was not fully representative of the total population (Murrells et al., 2015).

Primary Health Care Research \& Development 2016; 17: 524-529 
PNs comprise the largest group of nurses working in $\mathrm{PHC}-42 \%$ in 2015 (Nursing Council of New Zealand, 2015) - and as our study has shown they carry out $60 \%$ of all nurse consultations in PHC and require support to further develop this role within a multidisciplinary framework envisaged by the NZ PHC Strategy. Barriers reported by PNs against further expanding their role have included increased demands on their time (Finlayson et al., 2009) (also evidenced by less time spent with established patients) (Kenealy et al., 2004), an increase in administrative work, having a larger number of sick patients enrolled and a lack of paid release time for further study (Finlayson et al., 2009).

This survey reports on the extent of PHC nursing initiatives and provides information for the PHC nursing workforce on capacity and capability for further expansion within complex and multifactorial PHC systems (McCormack et al., 2002, Scott and Coote, 2010). Our results could be used for future planning, funding, workload management, training and educational opportunities.

\section{Study limitations}

There is potential for error in calculating the number of diabetes consultations per week by the sampled nurses as the midpoint in the category of hours that the nurses selected was used (Table 1). However, the total calculated number of diabetes consultation per week is likely to be conservative as 40 hours was used for those who worked $\geqslant 40$ hours per week, and $37 \%$ of the nurses worked for more than eight hours on the randomly selected day. Another limitation of our findings is that the survey was carried out in 2006-2008, and changes may have occurred in the number of diabetes patients consulted by nurses since then. The two major changes in national policy in 2012 have been the replacement of the annual free review of diabetes patients with a 'Diabetes Care Improvement Package' that allows more flexible use of funds (Ministry of Health, 2012) and the opportunity for diabetes nurse specialists to become designated prescribers (Health Workforce New Zealand, 2013). It is not clear what impact these changes might have on the role of PNs. In addition, this survey primarily represents urbanbased PHC nurses and may not reflect nursing practice in rural areas. Despite this, we are confident that the inferences made about the number

Primary Health Care Research \& Development 2016; 17: 524-529 of diabetes consultations PHC nurses undertaken per day is representative of PHC nurses working throughout the greater Auckland area because of the very high $86 \%$ response rate, random sampling of the nurses and the randomly selected day each nurse had worked.

\section{Conclusion}

This survey quantifies the number of diabetes consultations by PHC nurses in a large multicultural urban population. PNs carry out the largest number of community diabetes consultations by nurses. Their major contribution needs to be incorporated into future planning of the community management of diabetes.

\section{Acknowledgements}

The authors thank the primary health care nurses throughout Auckland who generously participated in this study.

\section{Funding}

Funding for this survey was provided by Novo Nordisk, the Charitable Trust of the Auckland Faculty of the Royal New Zealand College of General Practitioners and the New Zealand Ministry of Health.

\section{Conflicts of Interest}

No conflicts of interest have been declared by the authors.

\section{References}

Daly, B., Arroll, B., Kenealy, T., Sheridan, N. and Scragg, R. 2015: Management of diabetes by primary health care nurses in Auckland, New Zealand. Journal of Primary Health Care 7, 42-49.

Daly, B., Arroll, B., Sheridan, N., Kenealy, T. and Scragg, R. 2013a: Characteristics of nurses providing diabetes community and outpatient care in Auckland. Journal of Primary Health Care 5, 19-27.

Daly, B., Kenealy, T., Arroll, B., Sheridan, N. and Scragg, R. 2013b: Contribution by primary health nurses and general practitioners to the Diabetes Annual Review (Get Checked) programme in Auckland, New Zealand. New Zealand Medical Journal 126, 15-26. 
Daly, B., Arroll, B., Sheridan, N., Kenealy, T. and Scragg, R. 2014a: Diabetes knowledge of nurses providing community care for diabetes patients in Auckland, New Zealand. Primary Care Diabetes 8, 215-23.

Daly, B., Arroll, B., Sheridan, N., Kenealy, T., Stewart, A. and Scragg, R. 2014b: Foot examinations of diabetes patients by primary health care nurses in Auckland, New Zealand. Primary Care Diabetes 8, 139-46.

Daly, B., Kenealy, T., Arroll, B., Sheridan, N. and Scragg, R. 2014c: Do primary health care nurses address cardiovascular risk in diabetes patients? Diabetes Research and Clinical Pracitice 106, 212-20.

Finlayson, M., Sheridan, N. and Cumming, J. 2009. Evaluation of the implementation and intermediate outcomes of the primary health care strategy second report: nursing developments in primary health care 2001-2007. Wellington, New Zealand: Health Services Research Centre Victoria University.

Health Workforce New Zealand. 2013: Registered nurse prescribing in diabetes care: 2012 managed national roll out project report. Retrieved 10 November 2015 from http:// www.nzssd.org.nz/healthprofs/13\%2010\%20Registered $\% 20$ Nurse \%20Prescribing \%20in \%20Diabetes \%20Care\%20final \%20report.pdf

Kenealy, T., Arroll, B., Kenealy, H., Docherty, B., Scott, D., Scragg, R. and Simmons, D. 2004: Diabetes care: practice nurse roles, attitudes and concerns. Journal of Advanced Nursing 48, 68-75.

McCormack, B., Kitson, A., Harvey, G., Rycroft-Malone, J., Titchen, A. and Seers, K. 2002: Getting evidence into practice: the meaning of 'context'. Journal of Advanced Nursing 38, 94-104.

Ministry of Health. 2008: A portrait of health: key results of the 2006/07 New Zealand Health Survey Retrieved
10 November 2015 from http://www.health.govt.nz/publication/ portrait-health-key-results-2006-07-new-zealand-health-survey

Ministry of Health. 2012: Diabetes care improvement package. Retrieved 10 November 2015 from http:/www.health. govt.nz/our-work/diseases-and-conditions/diabetes/diabetescare-improvement-package

Ministry of Health. 2014: The New Zealand Health Survey. Annual update of key findings 2013/14. Retrieved 10 November 2015 from http://www.health.govt.nz/publication/annualupdate-key-results-2013-14-new-zealand-health-survey

Murrells, T., Ball, J., Maben, J., Ashworth, M. and Griffiths, P. 2015: Nursing consultations and control of diabetes in general practice: a retrospective observational study. British Journal of General Practice 65, e642-648.

New Zealand Society for the Study of Diabetes. 2009: League table for adult diabetes specialist physician services in New Zealand. Retrieved 10 November 2015 from http://www. nzssd.org.nz/healthprofs/workforce_physician.html

Nursing Council of New Zealand. 2015: The New Zealand Nursing Workforce: a profile of nurse practitioners, registered nurses and enrolled nurses 2014-2015. Retrieved 10 November 2015 from http://www.nursingcouncil.org.nz/ content/download/1508/6910/file/Workforce \%20statistics \% 20Nursing \%2031\%20March\%202015.pdf

Robinson, T., Simmons, D., Scott, D., Howard, E., Pickering, K., Cutfield, R., Baker, J., Patel, A., Wellingham, J. and Morton, S. 2006: Ethnic differences in type 2 diabetes care and outcomes in Auckland: a multiethnic community in New Zealand. New Zealand Medical Journal 119, U1997.

Scott, A. and Coote, W. 2010: Do regional primary-care organisations influence primary-care performance? A dynamic panel estimation. Health Economics 19, 716-29. 